\title{
Study Investigator Signature Text
}

National Cancer Institute

\section{Source}

National Cancer Institute. Study Investigator Signature Text. NCI Thesaurus. Code C94286.

The signed name of the investig ator who is responsible for completing a form or report for a clinical trial. 